\title{
Decision Making in Sustainable Development: Some Methods to Evaluate Energy and Nonrenewable Resources Waste When Using Some Plastics*
}

\author{
Lol-chen Alegria Mejia, Carlos E. Escobar Toledo, Bárbara M. Ramírez Rayle \\ Department of Chemical Engineering, National University of Mexico (UNAM), Mexico City, Mexico \\ Email: carloset@unam.mx
}

Received May 21, 2012; revised June 24, 2012; accepted July 9, 2012

\begin{abstract}
This paper explores a decision making model for a multidisciplinary problem in nature. This problem considers the role of energy use in sustainable development and the potential sources to increase energy efficiency during its whole life cycle; it also deals with multicriteria decision making of plastic materials used in a day to day basis. Exergy analysis of plastic materials used to the manufacture of disposable polyethylene bags comparing them with other materials that can be used for substitution will be important to take decisions. We are also interested in plastic poly (ethylene Terephthalate or PET) bottles. The calculation of the incoming and outgoing Exergy flows during the production processes are carried out. The Exergy loss considering the sustainability concept, Green House Gases emissions, real energy flows needed to the chain of processes, material balances in the productions chains and value added, are presented as a set of criteria to make decisions of alternative materials including the actual ones. A case study for Mexico's market will be developed in order to prove the methodology. It offers some interesting data about consumption and production of bags and bottles.
\end{abstract}

Keywords: Sustainability; Exergy; Polyethylene Bags and PET Bottles Uses and Recycling; Multiple Criteria Model to Aid Decision Making

\section{Introduction}

Scientific and technological development enables to provide a wide variety of goods and services in order to satisfy our day to day needs, they also put at risk the quality and longer-term viability of the biosphere as a result of unwanted, "second order" effects [1]. These effects are those related to pollution, as mainly global warming, acid rain, water and soil contamination, etc.

Over a period of some 15 - 20 years, the international community has been grappling with the task of defining the concept of "sustainable development". Starting from Brundlandt report on sustainability that states sustainable development as: development that meets the needs of the present without compromising the ability of future generations to meet their own needs [2], it continues to be evident that sustainability is a multidisciplinary topic including challenges for technology, based on the efficient use of energy. A lot of parameters and criteria are essential for long-term global sustainability.

\footnotetext{
*We thank to Programa de Apoyo a Proyectos de Investigación e Innovación Tecnológica project number IN102710, from DGAPAUNAM for the grant allocated to us in order to do this paper.
}

This research focuses on two theses. The first one is that plastic bags and bottles for individual use are not efficient on the energy efficiency viewpoint, considering also global pollution and waste problems, within their full life cycle: production, use and disposal.

During production of those items, a waste of non renewable resources and Green House Gas (GHG) emissions are present and their lifetime use is very short, mainly at the end of their use, i.e. their final use. Then, the efficient use of energy, avoiding also energy and raw material waste are essential for long-term global sustainability.

Our second thesis concerns different materials or ways to use plastics getting longer use life cycle, saving energy and avoiding pollution; we strongly believe that using technology-driven sustainability and economic growth, without wasting non renewable resources and energy, is possible.

General relations about energy efficiency, Exergy, and a thermodynamic parameter, such as relative irreversibility, are presented first.

Then the whole chain of production since natural gas liquids or crude oil is the start point of production chains 
until the production of plastic bags and bottles are considered to perform the Exergy analysis, comparing them with other materials with a less energy and non-renewable resources consumption.

To choose which material (including the actual ones) is better and to choose the outranking substitution alternatives, Multicriteria methods [3] can be used, considering several criteria such as: Exergy efficiency and ireversibility; non renewable resources used over their life cycle; profit are suitable criteria to remedy the present plastic materials waste in their full energy life cycle and minimize GHG emissions.

Generally, sustainability is associated with ecology and energy; however, it has major implications, since it is a general concept that covers since the system's birth until implementation of tasks for improvement quality of human life and the environment.

The quantification of sustainability is important but also difficult because of the relations between energy, economic, ecological and social factors.

In this work, "Exergy" concept is understood as the maximum amount of work which can be produced by a stream of matter, heat or work as it comes to equilibrium with reference environment; it can be linked with environmental impacts because through the Exergetic Analysis, the irreversibility in the process can be known and thus, it can lead to a better behavior to increase energy efficiency.

The Life Cycle Analysis (LCA) is a useful tool in many cases to assess the environmental impacts producing by the processes. ISO14040: 2006 [4] defines it as: Compilation and evaluation of the inputs, outputs and the potential environment impacts of a product system throughout its life cycle.

In using the above concepts and methods to apply to plastic materials, we present in Figure 1 all associated concepts that can be viewed integrally.

\section{Methodology}

A methodology has been created in order to perform the whole analysis considering the different stages, as it follows in Figure 2.

Considering the diagram presented in the above figure, it will be described each one of the involved concepts in the following paragraphs.

\subsection{Exergy and Energy Analyses}

One of the objectives of this work is to show Exergy analysis as a powerful instrument to address sustainable

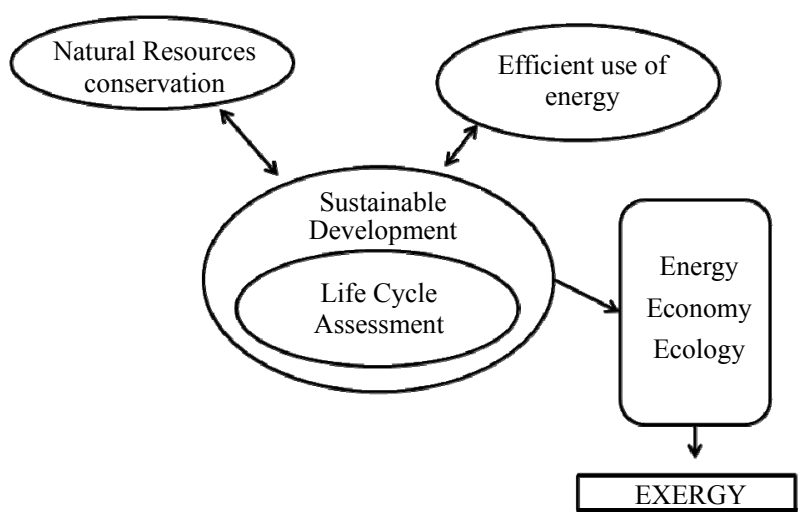

Figure 1. Methods and concepts used in this paper.

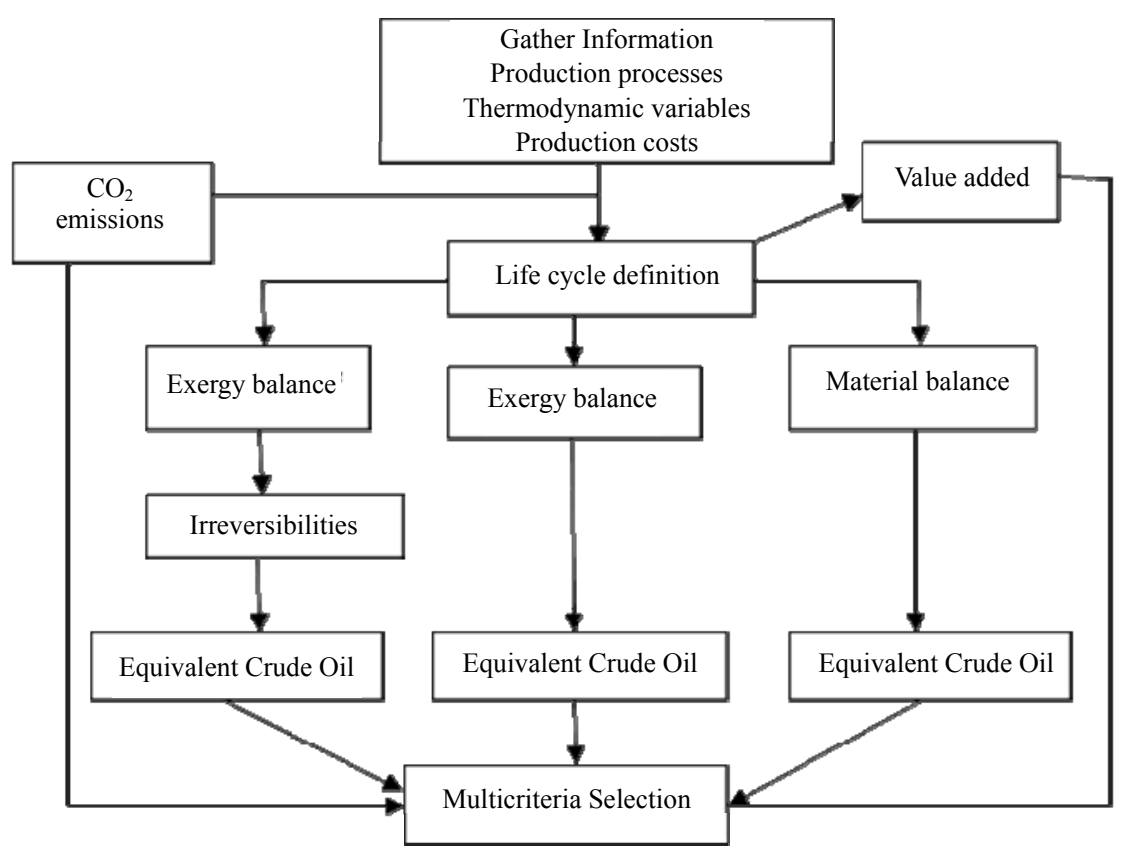

Figure 2. Methodology used in this paper. 
development. An important aspect of sustainable development is the minimization of total irreversibility caused by the use of non-renewable resources. The Exergy method has as evaluation basis, thermodynamic losses follows from the second law of Thermodynamics. Exergy is then defined as the maximum potential work of a material or an energy form, in relation with its environment. Actually there exist only in irreversible processes. In an Exergy balance, the irreversibility rate of a steady flow process can be calculated, combining the steady flow energy equation (First Law) with the expression for the entropy production rate (Second Law). Some works using Exergy analysis for life cycle of products are found in the literature such as those of Dewulf and Langenhove [5].

Exergy constrained in a system represents a resource [6]. When emitted to the environment, Exergy becomes unconstrained and represents a driving potential for environmental damage. On the other hand, when decreasing the Exergy efficiency of a process causes an increase in the related environmental impact associated with the process, trough resource degradation, or waste Exergy emissions.

To determine the thermodynamic perfection of a system, not only processes that occur within the system have to be taken into account, but also all kinds of interaction between energy and material flows outside the system's boundaries. Only then, the system's actual performance and its impact on the environment can be evaluated. The irreversibility during the complete life cycle allows to evaluate the degree of thermodynamic perfection of the production processes and to conduct the assessment of the whole process chain [7].

The Exergy method is defined as a measure of the potential or quality work of different forms of energy in relation to a given environment. An Exergy balance applied to a single process or in a whole plant or even for a chain of processes, beginning from a given raw material to a defined product, tell us how much of the usable potential work or Exergy, supplied as an input to the system under consideration has been consumed by the process. The loss of Exergy or irreversibility provides a measure of process inefficiency.

On basis of the life cycle approach in combination with Exergy analysis a method is developed, which is called the Exergetic Life Cycle Analysis (ELCA). This method is an extension to the already established method of Life Cycle Assessment [8]. The ELCA should be a part of every LCA, because life cycle irreversibility is the most appropriate parameter for the depletion of natural resources. The irreversibility also called Exergy loss, is calculated by setting up the Exergy balance and taken the difference between all incoming and outgoing Exergy flows or:

$$
I=\sum_{\text {in }} E_{i}-\sum_{\text {out }} E_{j}
$$

where " $\Gamma$ " is the irreversibility of the process and, " $E$ " represents Exergy.

Exergy is divided mostly in two streams: physical Exergy and chemical Exergy. Chemical Exergy reflects the resource's deviation in chemical composition from the reference environment. For the majority of natural resources, this chemical Exergy is the most important contribution to its exergetic value.

From the constituents of the elements, the chemical Exergy of any resource substance can be calculated through thermo-chemistry. Given the standard Gibbs free energy of formation $\Delta G^{0}(\mathrm{~kJ} / \mathrm{mol})$, the chemical Exergy of a compound $i, \quad e_{c h, i}^{0}(\mathrm{~kJ} / \mathrm{mol})$, is computed by:

$$
e_{c h}^{0}=\Delta G^{0}+\sum v_{e l} e_{c h, e l}^{0}
$$

where $v_{e l}, e_{c h, e l}^{0}$ are the number of moles and the standard chemical exegy $(\mathrm{kJ} / \mathrm{mol})$ of the elements that constitute the compound.

In order to calculate the reaction free energy $\Delta G^{0}$, one extracts the enthalpy of formation $H_{f}^{O}(\mathrm{~kJ} / \mathrm{mol})$ and absolute entropy $S^{0}(\mathrm{~kJ} / \mathrm{mol} \mathrm{K})$ for both reagents and reaction products from thermo-chemical databases. $\Delta G^{0}$ is then obtained through:

$$
\begin{aligned}
\Delta G^{0}= & \left(\sum H_{f, \text { productos }}^{0}-\sum H_{f, \text { reagents }}^{0}\right) \\
& -T_{0}\left(S_{f, \text { products }}^{0}-S_{f, \text { reagents }}^{0}\right)
\end{aligned}
$$

For some compounds thermo chemical data and/or chemical composition are unknown (e.g., solid fuels, oil, etc.), this makes it difficult to determine the entropy of reaction with a reasonable degree of accuracy [9]. Szargut and Steward [10] assumed that the ratio of chemical Exergy $e^{0}$, to the net calorific value (NCV) for solid and liquid industrial fuels is the same as for pure chemical substances having the same ratios of chemical constituents. This ratio is denoted by $\varphi$ :

$$
\varphi=\frac{e^{0}}{N C V}
$$

For organic substances contained in solid fossil fuels consisting of $\mathrm{C}, \mathrm{H}, \mathrm{O}$ and $\mathrm{N}$, there are empirical data to perform calculations about exergy. Some other empirical relations can be found in Kotas and Szargut [9].

Exergy analysis has several uses in LCA, e.g., as a rough indicator for total environmental impact, or when performing an improvement assessment for identifying losses of useful energy. Exergy may also be used as a measure of the depletion and use of energy and material resources [11].

There are two main advantages of Exergy analysis. First, all materials can be expressed in the same unit, in Joules of Exergy. Second, this basis allows a thorough 
and objective analysis of industrial processes with respect to their resource inputs and process efficiencies. Assessment of sustainability is based on calculation of cumulative Exergy consumption (CExC), taking into account resources required to generate the product [12].

In our two cases, we will start the Exergy analysis from crude oil processing until the production of low density polyethylene (LDPE) and polyethylene terephthalate resins (PET). But not only, energy full cycle analysis (considering only the first law of thermodynamics concept), can show that polyethylene bags have a better performance during its life cycle than no matter other materials including those bags made with renewable materials [13].

\subsection{Multicriteria Methods}

This paper uses the PROMETHEE-GAIA, a multicriteria decision aid method (MCDA). Let us consider the following Multicriteria problem [14]: $\operatorname{Max}\left\{g_{1}(a), g_{2}(a), \cdots\right.$, $\left.g_{j}(a), \cdots, g_{k}(a) \mid a \in A\right\}$ where $A$ is a finite set of possible alternatives $\left\{a_{1}, a_{2}, \cdots, a_{\mathrm{i}}, \cdots, a_{n}\right\}$ and $\left\{g_{1}(\cdot), g_{2}(\cdot), \cdots\right.$, $\left.g_{j}(\cdot), \cdots g_{k}(\cdot)\right\}$ a set of evaluation criteria. There is no objection to consider some criteria to be maximized and the others to be minimized. The expectation of the decision maker is to identify an alternative optimizing all the criteria. In most cases at least technological, economical, and environmental criteria should always be taken into account. Multicriteria problems are therefore extremely important and request an appropriate treatment. The basic data of a Multicriteria problem consist of an evaluation of alternatives and criteria, as it is shown in Table $\mathbf{1 .}$

The solution of a Multicriteria problem depends not only on the basic data included in the evaluation table but also on the decision-maker himself. The best compromise solution also depends on the individual preferences of each decision-maker [15]. Consequently, additional information representing these preferences is required to provide the decision maker with useful decision aid.

\subsection{Life Cycle Analysis}

Life Cycle Analysis is a relative approach, which is structured around a functional unit. This functional unit defines what is being studied. All subsequent analyses

Table 1. Multicriteria matrix.

\begin{tabular}{cccccc}
\hline$a$ & $g_{1}(\cdot)$ & $g_{2}(\cdot)$ & - & $g_{j}(\cdot)$ & $g_{k}(\cdot)$ \\
$a_{1}$ & $g_{1}\left(a_{1}\right)$ & $g_{2}\left(a_{1}\right)$ & - & $a_{j}\left(a_{1}\right)$ & $g_{k}\left(a_{1}\right)$ \\
$a_{2}$ & $g_{1}\left(a_{2}\right)$ & $g_{2}\left(a_{2}\right)$ & - & $g_{j}\left(a_{2}\right)$ & $g_{k}\left(a_{2}\right)$ \\
$a_{3}$ & $g_{1}\left(a_{3}\right)$ & $g_{2}\left(a_{3}\right)$ & - & $g_{j}\left(a_{3}\right)$ & $g_{k}\left(a_{3}\right)$ \\
- & - & - & - & - & - \\
$a_{n}$ & $g_{1}\left(a_{n}\right)$ & $g_{2}\left(a_{n}\right)$ & - & $g_{j}\left(a_{n}\right)$ & $g_{k}\left(a_{n}\right)$ \\
\hline
\end{tabular}

are then relative to that functional unit, as all inputs and outputs in the Life Cycle Inventory (LCI) and conesquently the Life Cycle Impact Assessment (LCIA) profile are related to the functional unit.

\section{Exergetic Life Cycle Analysis (ELCA)}

Sustainable improvement processes or activities are achieved through the reduction of irreversibility, had a clear distinction between renewable and non-renewable resources to assess the sustainability of a process or activity [16]. This method began in 1977 with the work presented by Wall. This type of analysis applied to productive sectors may lead to understanding of how to improve the sustainability of the activities through the reduction of Exergy consumption. The methodology of ELCA is relatively the same of LCA, the difference is that the Inventory Analysis is more extensive, the mass and energy balances should be closed and the black boxes must be more simplified for inputs and outputs of production processes considered within the inventory. Also, the conditions and composition of the environment should be taken into account [17].

\section{Case Study}

\subsection{Goal and Scope Definition}

The goal of this study is to compare substitutions material for shopping bags and PET bottles using multicriteria decision making as it was described in 2.2.

Alternatives to polyethylene bags are: cotton (unbleached), polypropylene, paper (unbleached Kraft). We will compare them following the methodology described with the actual polyethylene bags including pro degradeing additives.

Because of the carrying capacity of the plastic bag, the functional unit is taken to be the use of 900 polyethylene bags and 675 paper bags (the number of single use bags to carry goods from a store to home equivalents to the use of one reusable bag were calculated). For PET bottles the substitution alternatives are glass and aluminum. The functional unit of PET study is 1 ton. (26,000 bottles of 1 liter volume) this calculation bases was used for the Exergetic Life Cycle Analysis and the atmospheric emissions.

\subsection{Materials}

As we have pointed out, five types of grocery bags were analyzed, three of them disposable: the commonly used plastic bag made from Low Density Polyethylene, a LDPE bag containing a pro degrading, unbleached Kraft paper bags and two reusable: a polypropylene fiber bag and a cotton bag. Polyethylene is not biodegradable mainly because it has large molecular weight and its large molecules cannot enter into the cells of microor- 
ganisms easily.

After many years of research, it has now been established that the mechanism of polyethylene biodegradetion, known as "oxo-biodegradation", involves two stages. They are: 1) abiotic (photo or thermo) oxidation, and 2) microbial biodegradation. In the first stage, polyethylene is oxidized leading to the reduction of its molecular weight significantly. Also, hydroxyl $(\mathrm{OH})$, carbonyl $(\mathrm{C}=\mathrm{O})$ and carboxyl $(\mathrm{COOH})$ groups are introduced into polyethylene chain leading to further oxidation of poly-ethylene.

Pro-oxidants (Pro degradings) are transition metal ion complexes and they are added to polyethylene in the form of either stearate or other organic ligand complexes. $\mathrm{Fe}^{3+}, \mathrm{Mn}^{2+}$ or $\mathrm{Co}^{2+}$ stearate are the most commonly used pro-oxidants. Polyethylene that has been oxidized by pro-oxidants will be more susceptible to microbial attack than the initial polyethylene film due to increased hydro philicity and presence of low molecular weight fragments [18].

PET is a thermoplastic obtained through a condensation reaction with two main raw materials: terephthalic acid and ethyleneglycol.

The glass is an inorganic substance hard, fragile, transparent and amorphous formed by silicon dioxide $\left(\mathrm{SiO}_{2}\right)$, sodium carbonate $\left(\mathrm{Na}_{2} \mathrm{CO}_{3}\right)$, calcium carbonate $\left(\mathrm{CaCO}_{3}\right)$ and feldspar. Glass production consists of a casting process at $1500^{\circ} \mathrm{C}$.

The main raw material in aluminum production is bauxite rocks, which are formed by aluminum mineral such as: gibbsite, boehmite and diaspore.

\subsection{Data Source}

For the case study the LCA is carried out with the aid of the software package SimaPro 7.1. Also Aspen Plus database is used for thermo-chemical data. Chemical technology encyclopedias have also been consulted [19], as well as existing and publicly available Life Cycle Assessments reports. The plastics Europe reports developed by Boustead Consulting also were consulted. The Process Economic Program reports are mainly from where the information on raw materials, by products and utilities come from [20].

\subsection{Considerations}

At the end of its first use, PE and PET can be simply disposed in the environment without any conversion. Alternatively, they can be converted trough incineration or trough land filling with methane captation for heat and/or electricity production. They also can be recycled resulting in the same plastics if it is possible.

Of course recycling systematically generates the highest output. In the case of Polyethylene it is only possible to recycle $60 \%$ in the best case.

Taking Mexico consumption of plastic bags and bottles, we have dimensioned the pollution problem, energy degradation and hydrocarbons waste. In Mexico it was consumed a mean of Polyethylene high and low density, it is approximately of 600,000 ton/year. Considering that 900 bags are equivalent to $5.04 \mathrm{Kg}$, this is equivalent to 107,100 million bags/year. The gross benefit for producers are about 2 US\$ $/ \mathrm{kg}$. It means a good business. From the point of view of non renewable resources waste, in Mexico are crapped an equivalent of 8.25 million US\$/ day (considering a crude oil international price of 84 US\$/barrel).

Taking as base bottles of 1 liter, Mexico has produced 9760 millions of bottles/year. In this case the gross margin benefit is more or less $0.060 \$$ bottle. Only $10 \%$ of these bottles are really recycled effectively. In the world, as a consequence there is an important surplus of raw material, i.e. Poly (ethylene Terephthalate). This implies that recycling business is no longer a good one at least in the short term.

\section{Results}

\subsection{PE Bags versus Alternative Materials Bags}

Table 2 summarizes the input and output flow of Exergy during the selected production processes for the $\mathrm{PE}$ and possible substitute bags. In such way, it has been possible to identify the life cycle steps with the main Exergy losses due to the process irreversibility and to the environmental pollutant releases.

Low Density Polyethylene was produced by a high pressure process autoclave reactor.This gives a total of

Table 2. Exergy flows of the different alternatives for shopping bags all in MJ/f.u.

\begin{tabular}{lccc}
\hline \multicolumn{4}{c}{ Disposable } \\
\hline & $\begin{array}{c}\text { LDPE } \\
\text { (filmgrade) }\end{array}$ & $\begin{array}{c}\text { LDPE+ Pro } \\
\text { degrading }\end{array}$ & $\begin{array}{c}\text { Unbleached } \\
\text { Kraft Paper }\end{array}$ \\
\hline Exergy Inputs & 933.733 & 952.33 & 4054.086 \\
Exergy Outputs & 689.728 & 692.7089 & 561.51 \\
Irreversibility & 236.527 & 251.5312 & 3484.78 \\
Emissions & 7.478 & 8.0899 & 7.796 \\
Total Exergy losses & 244.005 & 259.6211 & 3492.576 \\
\hline & \multicolumn{2}{c}{ Reusable } & - \\
\hline & PP fiber & $\begin{array}{c}\text { Cotton } \\
\text { (Unbleached) }\end{array}$ & - \\
\hline Exergy Inputs & 19.0984 & 294.491 & - \\
Exergy Outputs & 17.08 & 1.757 & - \\
Irreversibility & 1.887 & 292.623 & - \\
Emissions & 0.1314 & 0.111 & - \\
Total Exergy losses & 2.0184 & 292.734 & - \\
\hline
\end{tabular}


Exergy losses of 244.005 MJ/f.u. for the total Polyethylene production. Considering the characteristics of composition of ox degradable bags (97\% LDPE and 3\% additive), the total Exergy losses for polyethylene degradeable bags are $259.6 \mathrm{MJ} /$ f.u. As for bags made of unbleached Kraft paper, the total Exergy losses for this process are $3492.576 \mathrm{MJ} / \mathrm{f}$.u. In the case of reusable bags, the life cycle of Polypropylene, manufactured by a bulk slurry phase loop reactor process, presents a total of $2.018 \mathrm{MJ} / \mathrm{f}$.u. Exergy losses. And, we found a total of $292.73 \mathrm{MJ} /$ f.u. Exergy losses for the cotton bags.

Total Exergy outputs do not take into account Exergy of emissions since they are considered as losses, therefore emissions are not considered for the calculations of irreversibility related to the processes. Although other emissions to air, water and soil are not included. $\mathrm{CO}$, methane, $\mathrm{SO}_{2}$ and mostly $\mathrm{CO}_{2}$ emissions are the main substances related to pollution.

Table 3 illustrates the results of the Exergy analysis, which represents the Exergy destruction by process ireversibility associated with each production stage on the life cycle of the examined materials. As can be seen from the columns, the production of unbleached Kraft paper destroy the highest quantity of Exergy, which represents a much more relevant input than PE bags from the view point of Exergy consumption. Table 3 shows the emissions embedded within the life cycle of the alternatives analyzed.

The production of low density polyethylene bags with an ox degrading additive has the highest Exergy embedded on emissions. From Table 3, it is clear that the production of 1 polypropylene bag that is equivalent to the use of 900 PE bags, involves the lowest losses of Exergy. These data suggest that the employment of alternative materials instead of Polyethylene for the production of retail shopping bags is not always the best choice, even if the material inputs are lower between the functional units like is the case of cotton reusable bags.

\subsection{Multicriteria Decision Making in the Bags Case}

In the end of the methodology that has been presented above, we will use PROMÉTHÉE-GAIA multicriteria decision aid tool. Then for taking a decision about the substitute materials or the recycling process, they should be measured with various criteria, using as case study the Mexico's poor development in sustainable issues

Minimize: process irreversibility in the whole life cycle.

Minimize: non renewable resources used in its life cycle.

Minimize: real quantity of energy in each one of the processes involved in the life cycle of all alternatives.

Maximize: end product value (total cost of production plus $25 \%$ on ROI (Return on Investment).

Minimize: GHG in the whole life cycle of each alternative.

Using the results of each variable calculated according with our methodology, we present the results of Multicriteria solver Decision Lab, as follows (Figure 3).

According to the ranking obtained by PROMETHEE, the bags made from Propylene and Cotton are the best material based on the criteria considered (Irreversibility, real energy, mass balance, and unit product value). Taking into account another criterion named GHG, Green House Gases, mainly $\mathrm{CO}_{2}$ during the whole LCA, the results have changed taking into account the preference order.

Nevertheless the bags made from polypropylene are always the better alternative.

\subsection{The PET Case}

We have performed the calculations for PET manufac-

Table 3. $\mathrm{CO}_{2}$ emissions for the alternatives for bag manufacturing.

\begin{tabular}{ccc}
\hline Material & $\mathrm{kg} \mathrm{CO}_{2} / \mathrm{f} . \mathrm{u}$. & $\mathrm{MJ} / \mathrm{f} . \mathrm{u}$. \\
\hline LDPE (film grade) & 16.559 & 7.478 \\
LDPE + Pro degrading & 17.914 & 8.090 \\
Unbleached Kraft Paper & 17.263 & 7.796 \\
PP fiber & 0.291 & 0.131 \\
Cotton (Unbleached) & 0.246 & 0.111 \\
\hline
\end{tabular}

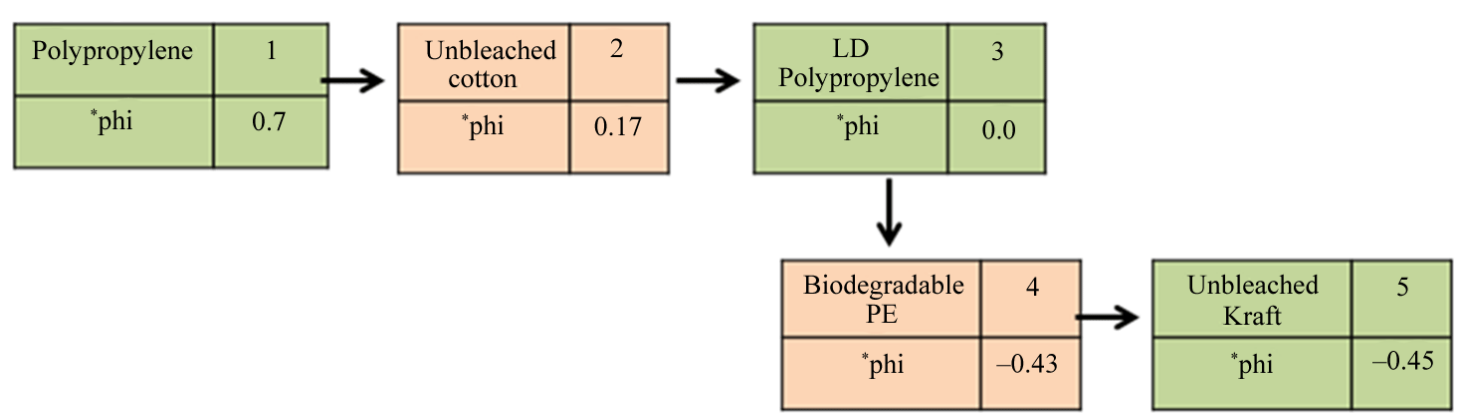

Figure 3. Multicriteria results for bags. 
turing process from terephthalic acid and ethlyleneglycol considering de input-product coefficient of PEMEX [21]. Table 4 shows the exergies with their irreversibility of PET manufacturing. The functional unit is 1 ton PET (26,000 bottles of 1 liter).

In the ELCA for the recycling alternative; there is a consumption of $91.15 \mathrm{MJ} / \mathrm{Kg}$ PET with which it is possible to obtain the same Exergy of pure PET $(23,705$ $\mathrm{MJ} / \mathrm{Ton} . \mathrm{PET}$ ) which in principle can be interpreted as one of the biggest advantage of this material [12].

\section{Recycling Process of PET}

The calculation of PET recycling is presented in Table 5.

The net flux of preference shows that the substitution of primary PET bottles can be done through recycling aluminum and recycling PET because these two options present positive fluxes. Also, we can observe that the glass bottles in primary and recycling processes have a negative performance. On the other hand, primary aluminum represents the worst performance mainly due to the electrolytic process.

Considering that results shown above are not consistent, it was decided to divide the problem in two clusters. First one with primary materials and the second one with recycled materials. The results once a multi-criterion was performed were:

PET $>$ Glass $>$ Aluminum: primary materials

Aluminum $>$ PET $>$ Glass: recycled materials

Also it was decided to propose a substitution strategic path consisting in replacing the growth annual rate (10\%) with recycled aluminum cans and PET recycled bottles.

The multicriteria results are shown in Figure $\mathbf{4}$ below.

\section{Conclusions}

Exergy aspects of the substitution problem between plastic bottles and bags for other materials more exergy adequate are presented in this study. These materials are: PET, with reuse consideration and better Exergetic Life Cycle Analysis. We also analyzed Polypropylene big bags and cotton as a natural fiber bag alternative.

Considering that results shown above are not consistent, it was decided to divide the problem in two clusters. First Exergy aspects of the substitution problem between plastic bottles and bags for other materials more exergy adequate are presented in this study. These materials are: PET, with reuse consideration and better Exergetic Life Cycle Analysis. We also analyzed Polypropylene big bags and cotton as a natural fiber bag alternative.

Some concluding remarks which can be extracted from this study are as it follows:

(a) From PE material balance, we have 0.207 crude oil barrels/PE bags (f.u.), equivalent to $17.46 \mathrm{US} \$ /$ f.u., taking an export price of crude oil of $84.4 \mathrm{US} \$ / \mathrm{bl}$.

(b) From the energy balance, we obtained $110.63 \mathrm{MJ} / \mathrm{PE}$ bags (f.u.); that quantity and considering a crude oil heat value of $6263.6 \mathrm{MJ} / \mathrm{bl}$, equals to 0.0176 barrels of crude oil per f.u. or $3.5 \mathrm{bl} /$ ton PE.

(c) From PET material balance, we have 8.8 crude oil barrels/PET bottles (f.u.), equivalent to $742.72 \mathrm{US \$} /$ f.u., taking an export price of crude oil of $84.4 \mathrm{US \$ /}$ bl.

(d) From the energy balance, we obtained $5413 \mathrm{MJ} / \mathrm{PET}$

Table 4. Exergy flows of PET primary Process.

\begin{tabular}{lccc}
\hline Process & $\begin{array}{c}\text { Input Exergy } \\
(\mathrm{MJ} / \mathrm{uf})\end{array}$ & $\begin{array}{c}\text { Output Exergy } \\
(\mathrm{MJ} / \mathrm{uf})\end{array}$ & $\begin{array}{c}\text { Irreversibility } \\
(\mathrm{MJ} / \mathrm{uf})\end{array}$ \\
\hline Xylenes & 674,864 & 614,266 & 60,597 \\
p-xylene & 40,241 & 26,545 & 13,696 \\
Terephthalic acid & 45,585 & 18,122 & 27,463 \\
Ethane & 45,130 & 44,895 & 235 \\
Ethylene & 18,716 & 10,843 & 7873 \\
Ethylene oxide & 24,402 & 6693 & 17,709 \\
Ethylenglycol & 8936 & 7510 & 1426 \\
PET & 29,873 & 23,705 & 6168 \\
Bottles & 34,885 & 23,705 & 11,180 \\
& Atmospheric emissions: & & 4099 \\
\hline
\end{tabular}

Table 5. Exergy required and obtained for recycling of PET.

\begin{tabular}{cc}
\hline Exergy & $\mathrm{MJ} / \mathrm{uf}$ \\
\hline Input & 37,017 \\
Output & 23,980 \\
Atmospheric emissions & 1076 \\
\hline
\end{tabular}

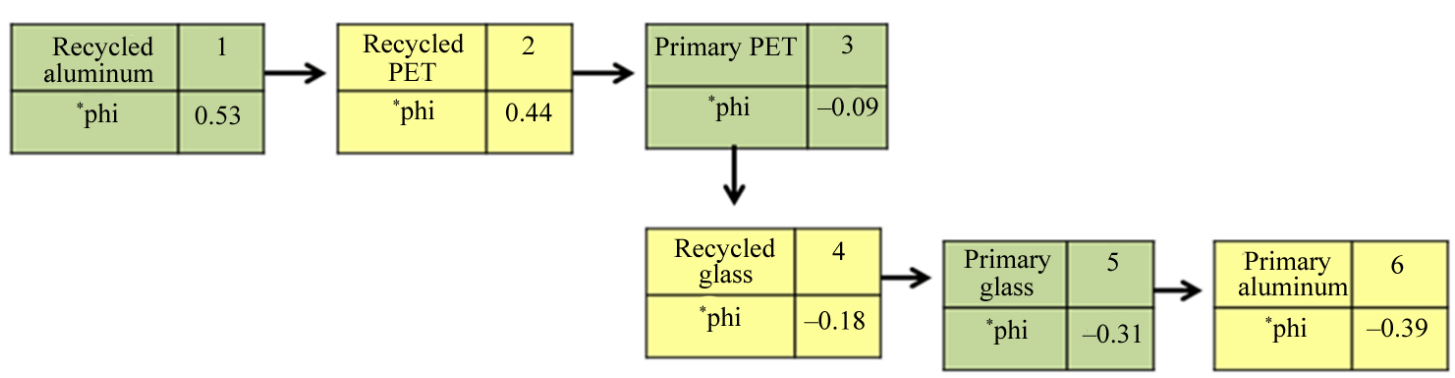

Figure 4. Multicriteria results for bottles. 
bottles (f.u.); that quantity is equal to 0.9 crude oil barrels/PET bottles (f.u.).

(e) According with the substitution strategic, it's possible to reduce 2.14 million of $\mathrm{CO}_{2 \text { eq }}$ and 10.28 million of barrels of crude oil in irreversibility's terms.

(f) Considering 160 billion bags consumed/year, it is equivalent to dispose into the landfill $4,754,2612$ US\$/day.

(g) Considering 9700 million bottles consumed/year, it is equivalent to dispose into the landfill $149,000,000$ US\$/day.

(h) The production of unbleached Kraft paper destroy the highest quantity of Exergy, which represents a much more relevant input than PE bags from the view point of Exergy consumption.

(i) The production of polyethylene bags with an ox degrading additive has the highest Exergy embedded on emissions.

(j) It is clear that the production of 1 polypropylene bag that is equivalent to the use of $900 \mathrm{PE}$ bags, involves the lowest losses of Exergy.

(k) These data suggest that the employment of alternative materials instead of Polyethylene for the production of retail shopping bags is not always the best choice.

(l) On the other hand the use of MCDA will be of a long interest for better decision making.

(m) The MCDA will give a measure of the production and delivery of useful work to consumers. This conversion efficiency tends to increase over time, when it is also a measure of technology and important economic factors.

(n) Exergy is a way to a sustainable development. In this regard, Exergy analysis is a very useful tool, which can be successfully used in the performance evaluation of waste materials with a very short life cycle. As another conclusion, the authors expect that the analyses reported here will provide the investigators with knowledge about how effective and efficient is to use its renewable resources. This very useful knowledge is also needed for identifying energy efficiency and/or energy conservation opportunities, as well as for dictating the right energy and Exergy management strategies of those items to be driven results for other types of materials or services.

Calculation of the overall destroyed Exergy to obtain the selected f.u. Exergy losses provides not only a measure of the energy availability or of the resource depletion but also the most sustainable criterion to reduce the Exergy losses and to improve the technological efficiency of the industrial production system. In this way, the Exergy analysis, associated with the energy and mass balances in an industrial process, represents an important advancement in the multi-criteria analysis of products.

The analysis of different alternative material for the manufacturing of retail shopping bags showed how selected production processes accounted for Exergy destruction and therefore resource depletion, and then a comparison can be made among the different alternatives within the same unit (MJ of Exergy).

The Total Exergy of air emissions in primary production of PET is considerable (4099.68 MJ) if we consider that these emissions are for functional unit ( 1 ton. PET $=$ 26,000 bottles).

The exergy analysis shows that the PET recycling process is an important option in the waste disposal treatment since the recycling irreversibility represents $9.38 \%$ with respect to primary process irreversibility. Also products obtained trough recycling processes are of sufficient quality to be used instead PET production.

\section{REFERENCES}

[1] G. P. Hammond, "Energy, Environment and Sustainable Development: A UK Perspective," Transactions of the Institution of Chemical Engineers, Part B: Process Safety and Environmental Protection, Vol. 78, No. 4, 2000. pp. 304-323. doi:10.1205/095758200530826

[2] G. H. Brundtland, et al., "Our Common Future, World Commission on Environment and Development (WCED)," Cambridge Energy Research Associates, Boletín, 2001.

[3] V. Philippe, "Multicriteria Decision-Aid," John Wiley \& Sons, Chichester, 1992.

[4] International Standard ISO 14040, "Environmental Management-Life Assessment-Principles and Framework," 2nd Edition, 2006.

[5] J. Dewulf and H. V. Langenhove, "Thermodynamic Optimization of Life Cycle of Plastics by Exergy Analysis," International Journal of Energy Research, Vol. 28, No. 11, 2004, pp. 969-976. doi:10.1002/er.1007

[6] I. Dincer and M. A. Rosen, "The Intimate Connection between Exergy and the Environment," In: A. Bejan and E. Mamut, Eds., Thermodynamic Optimization of Complex Systems, Kluwer Academic Publishers, Netherlands, 1999, pp. 221-230. doi:10.1007/978-94-011-4685-2 15

[7] R. L. Cornelissen, "Thermodynamics and Sustainable Development," Ph.D. Dissertation, University of Twente, Enschede, 1997.

[8] R. L. Cornelissen and G. G. Hirs, "Exergy Analysis in the Process Industry," In: A. Bejan and E. Mamut, Eds., Thermodynamic Optimization of Complex Systems, Kluwer Academic Publishers, Netherlands, 1999, pp. 195-208. doi:10.1007/978-94-011-4685-2 13

[9] T. J. Kotas, "The Exergy Method of Thermal Plant Analysis," Butterwood, London, 1995, p. 296.

[10] J. Szargut, D. R. Morris and F. R. Steward, "Exergy Analysis of Thermal, Chemical and Metallurgical Process," Hemisphere Pub. Corp., Washington DC, 1988.

[11] G. Finnveden and P. Östlund, "Exergies of Natural Resources in Life-Cycle Assessment and Other Applications," Energy, Vol. 22, No. 9, 1997, pp. 923-931. 


$$
\text { doi:10.1016/S0360-5442(97)00022-4 }
$$

[12] J. Dewulf and H. V. Langenhove, "Quantitative Assessment of Solid Waste Treatment Systems in the Industrial Ecology Perspective by Exergy Analysis," Environmental Science and Technology, Vol. 36, No. 5, 2002, pp. 11301135. doi: $10.1021 / \mathrm{es} 010140 \mathrm{o}$

[13] C. Chaffee and R. B. Yaros, "Life Cycle Assessment for Three Types of Grocery Bags-Recyclable Plastic; Compostable, Biodegradable Plastic; and Recycled, Recyclable," Boustead Consulting \& Associates Ltd., Progressive Bag Alliance Report, 2007.

[14] J. P. Brans and P. Vincke, "A Preference Ranking Organization Method: The Promethee Method for MCDM," Management Science, Vol. 31, No. 6, 1985, pp. 647-656.

[15] J. P. Brans and B. Mareschal, "Promethee V: MCDM Problems with Additional Segmentation Constraints," INFOR, Vol. 30, No. 2, 1992, pp. 85-96.

[16] M. Gong and G. Wall, "On Exergy and Sustainable Development, Part 2: Methods, Applications and Sugges- tions," Exergy International Journal, Vol. 1, No. 4, 2001, pp. 217-233. doi:10.1016/S1164-0235(01)00030-9

[17] J. Hernández Santoyo Tesis, "Sustentabilidad del Sector Petrolero en México Aplicando el Método de Análisis de Exergia," Dirigida por Dr. Ricardo Rivero Rodríguez, UNAM, 2006.

[18] F. M. Telmo Ojeda, E. Dalmolin, M. Forte, J. S. Jacques, F. M. Bentod and A. O. Camargo, "Abiotic and Biotic Degradation of Oxo-Biodegradable Polyethylenes," Polymer Degradation and Stability, Vol. 94, 2009, pp. 965970.

[19] R. E. Kirk and Othmer, "Encyclopedia of Chemical Technology," 5th Edition, John Wiley \& Sons, New York, 2004.

[20] Process Economics Program (PEP), "International YearBook," SRI-Consulting, Shao-Hwa Wang Editor, United States, 1998.

[21] Anuario Estadístico de PEMEX, 2010, pp. 30-42. www.pemex.com 